\title{
Assessment of risk factors affecting mortality in patients with colorectal cancer
}

\author{
Arif Emre ${ }^{1}$, Sami Akbulut ${ }^{2}$, Mehmet Sertkaya ${ }^{1}$, Muharrem Bitiren $^{3}$, Ilhami Taner Kale ${ }^{1}$, Ertan Bulbuloglu \\ ${ }^{1}$ Department of Surgery, Faculty of Medicine, Kahramanmaras Sutcu Imam University, Kahramanmaras, Turkey \\ 2Department of Surgery and Liver Transplant Institute, Faculty of Medicine, Inonu University, Malatya, Turkey \\ ${ }^{3}$ Department of Pathology, Faculty of Medicine, Kahramanmaras Sutcu Imam University, Kahramanmaras, Turkey
}

Gastroenterology Rev 2018; 13 (2): 109-117

DOI: https://doi.org/10.5114/pg.2018.73348

Key words: colorectal cancer, mortality, risk factors.

Address for correspondence: Sami Akbulut, Assoc. Prof., FICS, FACS, Department of Surgery, Faculty of Medicine, Inonu University, Malatya 44280, Turkey, phone: +90 422 3410660, fax: +90 422 3410036, e-mail: akbulutsami@gmail.com

\begin{abstract}
Introduction: The most important risk factors for colorectal cancer are age, high ASA score, anemia, low albumin, tumor stage, histopathological properties, tumor's relationship with adjacent tissues, positivity of surgical borders and timing of the surgical procedure.

Aim: To determine possible risk factors for mortality in patients undergoing colorectal cancer surgery.

Material and methods: The medical records of 101 consecutive patients who underwent colorectal cancer surgery at the Department of Surgery, Sutcu Imam University Faculty of Medicine, Kahramanmaras, Turkey between January 2008 and November 2015 were retrospectively reviewed. The patients were divided into two groups: surviving $(n=76)$ and deceased $(n=25)$ groups. The groups were compared in terms of several demographic, clinical, biochemical, and histopathological parameters. In addition, risk factors for mortality were analyzed with multivariate analysis. SPSS 22.2, PAST 3, and MedCalc 14 software packages were used for statistical analyses.

Results: The surviving and deceased groups significantly differed with respect to age $(p=0.001)$, hemoglobin $(p=0.001)$, lymph node positivity $(p=0.009)$, positive lymph node/total lymph node ratio $(p=0.012)$, thrombocyte count $(p=0.047)$, lymphovascular invasion ( $p=0.028)$, urgency of admission (emergency/elective) $(p=0.036)$, and postoperative carcinoembryonic antigen (CEA) level $(p=0.002)$. A receiver operating characteristics curve was drawn to determine the cut-off values of various parameters including age (63), hemoglobin (12.8), node positivity (3), positive/total lymph node ratio (0.435) and thrombocyte count (308), with age $(p<0.001)$, hemoglobin $(p<0.001)$, node positivity $(p=0.025)$ and positive/total lymph node ratio $(p=$ $0.024)$ being significantly different. A multivariate analysis revealed that age $(p=0.049)$, hemoglobin $(p=0.045)$, and positive/ total lymph node ratio $(p=0.025)$ were independent risk factors for mortality.

Conclusions: This study shows that older age, lower hemoglobin level, and high positive/total lymph node ratio were independent risk factors for mortality among colorectal cancer patients.
\end{abstract}

\section{Introduction}

Colorectal cancers are among the most common malignant disorders of the gastrointestinal tract. They rank third among cancers causing most deaths in the United States of America [1, 2]. Although a significant proportion of colorectal cancer cases emerge sporadically after the fifth decade of life, some cases are associated with hereditary syndromes or familial colorectal cancer, manifesting early in life. Risk factors for colorectal cancer include lifestyle, age, heredity, polyps, and gene mutations [2]. Many factors are possibly related to colorectal cancer mortality, morbidity, and prognosis. The most important patient-related risk factors for colorectal cancer are age, high ASA score, anemia, and low albumin level. The most important disease-related risk factors are tumor stage, histopathological properties (grade, lymph node involvement, lymphovascular invasion), tumor's relationship with adjacent tissues, positivity of surgical borders, treatment approach (surgery, neoadjuvant chemoradiotherapy, adjuvant chemoradiotherapy), and urgency of surgery (elective/emergency). These parameters have been ascribed varying levels of importance by different studies. 


\section{Aim}

Herein, we aimed to investigate various possible demographic, clinical, biochemical, and histopathological parameters as risk factors for mortality among patients undergoing colorectal surgery.

\section{Material and methods}

\section{Study design and definitions}

We retrospectively reviewed the medical records of patients who presented to Kahramanmaras Sutcu Imam University Medical Faculty, General Surgery Clinic or Emergency Department with signs and symptoms of colorectal disease and who subsequently underwent colorectal surgery between January 2008 and November 2015. This study was approved by Sutcu Imam University Faculty of Medicine, Institutional Review Board (Ethics Committee Approval No: 2016-02-08). A total of 101 patients with a histopathologically proven diagnosis of colorectal cancer met the inclusion criteria and were included in the study. Various parameters including age (years), sex (male/female), urgency of admission (elective/emergency), presenting complaint (bleeding/pain/anemia/weight loss/constipation/intestinal obstruction/diarrhea etc.), tumor location (caecum/ascending colon/transverse colon/descending colon/sigmoid colon/rectum), surgical procedure (right hemicolectomy/left colectomy/anterior resection/low anterior resection/total abdominal colectomy/abdominoperineal resection), surgical approach (open/laparoscopic), histopathologic features (adenocarcinoma/ mucinous carcinoma/rare types of colorectal cancer), tumor differentiation (well/moderately/poorly), perineural invasion (yes/no), lymphovascular invasion (yes/ no), positive lymph node $(\mathrm{N}+)$, positive lymph node/total lymph node $(\mathrm{N}(+) /$ total $\mathrm{N})$, tumor size $(\mathrm{mm})$, TNM stage, presence of metastasis or locoregional recurrence (yes/no), neoadjuvant chemotherapy (yes/no), neoadjuvant radiotherapy (yes/no), adjuvant radiotherapy (yes/ no), adjuvant chemotherapy (yes/no), preoperative and postoperative blood carcinoembryonic antigen (CEA)/CA 19-9 levels, preoperative blood parameters (hemoglobin, thrombocyte count, WBC, neutrophil \%, lymphocyte $\%$, lymphocyte/neutrophil \%, red cell distribution width (RDW), platelet distribution width (PDW)), duration of hospital stay (days), and follow-up and mortality status were recorded by two researchers (AE, MS).

The metastatic status of the disease was assessed on the basis of the findings of preoperative or postoperative computed tomography, intraoperative exploration, and colonoscopic examination. The presence of locoregional recurrences was assessed with postoperative colonoscopic examination and radiological modalities (computed tomography (CT), magnetic resonance imaging (MRI), positron emission tomography computed tomography (PET CT)). This study included patients with follow-up data that spanned at least 3 months. Therefore, patients operated on in November 2015 at the latest were included in the study. The survival status of the patients was determined using the National Death Certificate System. The follow-up duration was determined as the time between surgery and the latest outpatient clinic visit in the surviving patients and the time between surgery and death in the deceased ones. The disease-free survival was determined as the time between surgery and the detection of the first recurrence.

\section{Primary endpoints}

The primary objective of the present study was to determine the risk factors for mortality after colorectal surgery. To achieve that goal, the patients were assigned to two groups named as the surviving $(n=76)$ and deceased ( $n=25$ ) groups. The groups were compared with respect to study parameters. The independent predictors of mortality were also determined.

\section{Statistical analysis}

The statistical analyses were carried out using SPSS 22.0 (IBM Corporation, Armonk, New York, United States), PAST 3 (Hammer, Ø., Harper, D.A.T., Ryan, P.D. 2001. Paleontological statistics), and MedCalc 14 (Acacialaan 22, B-8400 Ostend, Belgium) software packages. The normality of the distribution of the single and multiple variables was tested using the Shapiro-Wilk test and the Mardia (Dornik and Hansen omnibus) tests, respectively, and the homogeneity of variances was tested using Levene's test. Continuous variables in the two independent groups were compared using the independent-samples $T$ test with bootstrap samples and the Mann-Whitney $U$ test with the Monte Carlo simulation technique. Paired data were compared with the Wilcoxon signed ranks test with Monte Carlo simulation. Categorical variables (presentation, tumor location, surgery type, pathology, metastasis status, radiochemotherapy usage) were analyzed with the Pearson $\chi^{2}$ and Fisher's exact tests with the Monte Carlo simulation technique. Odds ratios with confidence intervals were used to determine the most significant risk factor among statistically significant categorical risk factors. The Kaplan-Meier (product limit method) log rank (Mantel-Cox) method was used to determine the effects of the risk factors on mortality and survival; the Kaplan-Meier (product limit method) method was used to determine the effects of the statistically significant parameters on mortality and survival in a model. The variable-based cut-off value for the mortality was analyzed by a receiver operating characteristics (ROC) curve and 
the sensitivity and specificity values were calculated. The quantitative variables were expressed as mean \pm standard deviation (SD), and median (range) (maximum-minimum). The categorical variables were presented as $n$ (number) and percentage (\%). All data were reported with a confidence interval $(\mathrm{Cl})$ of $95 \%$, and a $p$-value of less than 0.05 was considered statistically significant for all statistical analyses.

\section{Results}

This study included 101 patients aged 29 and 87 years (mean \pm SD: $61.6 \pm 14.6$ ), of whom 59 were male and 42 were female. The initial admission symptom was rectal bleeding in 23 patients, constipation in 22 , obstructive complaints of varying intensity in 22 , abdominal pain in 22, anemia in 6 , weight loss in 4 diarrhea in 1 , and perianal abscess in 1 . Seventy-four patients presented to the general surgery clinic while the remainder presented to the emergency department. Twenty-five (24.8\%) patients died at postoperative follow-up and 76 (75.2\%) patients survived. Detailed demographic, clinical, and histopathological properties of both groups are presented in Tables I-V.

The two groups were compared for categorical variables using the Pearson $\chi^{2}$ and Fisher's exact tests. While there were significant differences between the two groups with respect to type of presentation ( $p=$ $0.036)$ and lymphovascular invasion ( $p=0.028)$, other categorical variables did not show any significant difference. The patients who presented to the emergency department and subsequently underwent emergency surgery had a mortality rate of $40.7 \%$ while those who presented on an elective basis had a mortality rate of $18.9 \%$. In other words, the mortality rate was 2.9 (95\% Cl: 1.1-7.7) times greater among patients who underwent emergency surgery compared to those who underwent elective surgery. An analysis of the lymphovascular invasion status revealed that the patients with lymphovascular invasion had a mortality rate of $41.2 \%$ and the rest of the patients had a mortality rate of $18.6 \%$. In short, the mortality rate was $3.1(95 \% \mathrm{Cl}$ : 1.1-7.9) times greater in patients with lymphovascular invasion compared to those without. Detailed information about categorical variables is provided in Table I.

The two groups were compared for continuous variables using the independent $t$ and Mann-Whitney $U$ tests. Significant differences were found for age $(p=0.001)$, hemoglobin $(p=0.001), \mathrm{N}(+)(p=0.009), \mathrm{N}(+) /$ total $\mathrm{N}$ $(p=0.012)$ and thrombocyte count $(p=0.047)$ between the two groups whereas other continuous variables did not show any significant difference. The details of these analyses are provided in Table II. A ROC curve was drawn to determine the statistically significant cut-off points for the statistically significant variables in Table II. The cut-off levels calculated for age $(\leq 63$ years vs. $>63$ years), hemoglobin ( $\leq 12.8$ vs. $>12.8), \mathrm{N}(+)$ ( $\leq 3$ vs. $>3)$ and $\mathrm{N}(+)$ /total $\mathrm{N}(\leq 0.0435$ vs. $>0.0435)$ were statistically significant whereas the one calculated for thrombocyte count ( $\leq 308$ vs. > 308) was not statistically significant. That is, the mortality risk of those aged $>63$ years was 7.7 (95\% Cl: 2.1-28.8) times greater than that of those aged $\leq 63$ years. The corresponding odds ratios for mortality calculated for hemoglobin, $\mathrm{N}(+)$ and $\mathrm{N}(+) /$ total $\mathrm{N}$ parameters were 13.9 (95\% Cl: 1.7-109.6), 7.1 (95\% Cl: 1.9-25.8), and 3.8 (95\% Cl: 1.4-10.7), respectively. The results of these analyses are shown in Table III. The sensitivity and specificity values of the cut-off points calculated for age, hemoglobin, $\mathrm{N}(+)$ and $\mathrm{N}(+)$ /total $\mathrm{N}$ parameters are shown in Figures 1-4.

The groups were also compared in terms of preoperative and postoperative serum CEA and CA 19-9 levels. Although there was no significant difference between the groups' preoperative CEA levels, the postoperative CEA levels significantly differed from each other $(p=0.002)$. In other words, a significant reduction occurred in the postoperative CEA levels compared to the preoperative CEA levels in the surviving group $(p=0.022)$ whereas the deceased group had an increased postoperative CEA level. The two groups did not show any significant difference in either preoperative or postoperative CA 19-9 levels. These analyses are shown in detail in Table IV.

Kaplan-Meier log rank (Mantel-Cox) analysis was used to analyze the effects of the statistically significant categorical and continuous variables in the univariate analysis on survival (Table V). A multivariate analysis revealed that initial presentation $(p=0.028)$, lymphovascular invasion $(p=0.005)$, age $(p=0.001)$, hemoglobin $(p=0.005), \mathrm{N}(+)(p=0.001), \mathrm{N}(+) /$ total $\mathrm{N}(p=0.001)$, and thrombocyte $(p=0.01)$ count were the significant independent predictors of mortality. The 5 -year survival rate was also calculated, which was $72.3 \%$ among patients who underwent elective surgery and $43.2 \%$ among those who underwent emergency surgery. The 5-year survival rates for lymphovascular invasion (no/yes), age $(\leq 63 />63)$, hemoglobin $(>12.8 / \leq 12.8)$, $\mathrm{N}(+)(\leq 3 />3), \mathrm{N}(+) /$ total $\mathrm{N}(\leq 0.0435 />0.0435)$, and thrombocyte count $(\leq 308 />308)$ were $73.1 \% / 39.6 \%$, $86 \% / 43.1 \%$, 93.3\%/58.2\%, 74.6\%/19.3\%, 79\%/40.1\%, and $82.6 \% / 57 \%$, respectively. The overall 5 -year overall survival rate was $64.6 \%$.

The predictors of mortality were also subjected to Cox regression backward stepwise analysis, the results of which are shown in Table VI. Accordingly, age $>63$ years $(p=0.049)$, hemoglobin $\leq 12.8(p=0.045)$, and $\mathrm{N}(+)$ /total $\mathrm{N}$ ratio $>0.0435$ significantly and independently predicted mortality. In other words, age $>63$ years 
Table I. Comparison of the surviving and deceased groups for the categorical variables

\begin{tabular}{|c|c|c|c|c|c|c|}
\hline Outcome & & $\begin{array}{c}\text { Surviving } \\
n(\%)\end{array}$ & $\begin{array}{c}\text { Deceased } \\
n(\%)\end{array}$ & $\begin{array}{l}\text { Total } \\
n(\%)\end{array}$ & $\begin{array}{c}\text { Odds ratio } \\
(95 \% \mathrm{Cl})\end{array}$ & $P$-value \\
\hline \multirow[t]{2}{*}{ Sex } & Female & $29(38.2)$ & $13(52.0)$ & $42(41.6)$ & & 0.249 \\
\hline & Male & $47(61.8)$ & $12(48.0)$ & $59(58.4)$ & & \\
\hline \multirow[t]{2}{*}{ Initial presentation } & Elective & $60(78.9)$ & $14(56.0)$ & $74(73.3)$ & $2.9(1.1-7.7)$ & 0.036 \\
\hline & Emergency & $16(21.1)$ & $11(44.0)$ & $27(26.7)$ & & \\
\hline \multirow[t]{5}{*}{ Tumor location } & Ascending colon & $11(14.5)$ & $6(24.0)$ & $17(16.8)$ & & 0.289 \\
\hline & Caecum & $14(18.4)$ & $1(4.0)$ & $15(14.9)$ & & \\
\hline & Rectum & $27(35.5)$ & $7(28.0)$ & $34(33.7)$ & & \\
\hline & Sigmoid & $19(25.0)$ & $8(32.0)$ & $27(26.7)$ & & \\
\hline & Transverse & $5(6.6)$ & $3(12.0)$ & $8(7.9)$ & & \\
\hline \multirow[t]{6}{*}{ Surgery } & Anterior resection & $17(22.4)$ & $5(20.0)$ & $22(21.8)$ & & 0.535 \\
\hline & Left hemicolectomy & $2(2.6)$ & $3(12.0)$ & $5(5.0)$ & & \\
\hline & Low anterior & $19(25.0)$ & $6(24.0)$ & $25(24.8)$ & & \\
\hline & Miles procedure & $5(6.6)$ & $1(4.0)$ & $6(5.9)$ & & \\
\hline & Right hemicolectomy & $27(35.5)$ & $7(28.0)$ & $34(33.7)$ & & \\
\hline & Total colectomy & $6(7.9)$ & $3(12.0)$ & $9(8.9)$ & & \\
\hline \multirow[t]{2}{*}{ Surgery type } & Open & $67(88.2)$ & $25(100.0)$ & $92(91.1)$ & & 0.108 \\
\hline & Laparoscopic & $9(11.8)$ & $0(0.0)$ & $9(8.9)$ & & \\
\hline \multirow[t]{3}{*}{ Pathology } & Adenocarcinoma & $56(73.7)$ & $23(92.0)$ & $79(78.2)$ & & 0.107 \\
\hline & Mucinous carcinoma & $12(15.8)$ & $2(8.0)$ & $14(13.9)$ & & \\
\hline & Other & $8(10.5)$ & $0(0.0)$ & $8(7.9)$ & & \\
\hline \multirow[t]{2}{*}{ Metastasis } & No & $66(88.0)$ & $18(72.0)$ & $84(84.0)$ & & 0.111 \\
\hline & Yes & $9(12.0)$ & $7(28.0)$ & $16(16.0)$ & & \\
\hline \multirow[t]{2}{*}{ Perineural invasion } & No & $45(66.2)$ & $11(44.0)$ & $56(60.2)$ & & 0.06 \\
\hline & Yes & $23(33.8)$ & $14(56.0)$ & $37(39.8)$ & & \\
\hline \multirow[t]{2}{*}{ Lymphovascular invasion } & No & $48(70.6)$ & $11(44.0)$ & $59(63.4)$ & $3.1(1.1-7.9)$ & 0.028 \\
\hline & Yes & $20(29.4)$ & $14(56.0)$ & $34(36.6)$ & & \\
\hline \multirow[t]{3}{*}{ Differentiation } & Well differentiated & $31(53.4)$ & $9(40.9)$ & $40(50.0)$ & & 0.441 \\
\hline & $\begin{array}{l}\text { Moderately } \\
\text { differentiated }\end{array}$ & $22(37.9)$ & $12(54.5)$ & $34(42.5)$ & & \\
\hline & Poorly differentiated & $5(8.6)$ & $1(4.5)$ & $6(7.5)$ & & \\
\hline \multirow[t]{2}{*}{ Neoadjuvant RT } & No & 59 (81.9) & $21(95.5)$ & $80(85.1)$ & & 0.176 \\
\hline & Yes & $13(18.1)$ & $1(4.5)$ & $14(14.9)$ & & \\
\hline \multirow[t]{2}{*}{ Neoadjuvant CT } & No & $59(81.9)$ & $21(95.5)$ & $80(85.1)$ & & 0.176 \\
\hline & Yes & $13(18.1)$ & $1(4.5)$ & 14 (14.9) & & \\
\hline \multirow[t]{2}{*}{ Adjuvant RT } & No & $46(86.8)$ & $13(81.3)$ & $59(85.5)$ & & 0.687 \\
\hline & Yes & $7(13.2)$ & $3(18.8)$ & $10(14.5)$ & & \\
\hline \multirow[t]{2}{*}{ Adjuvant CT } & No & $23(41.1)$ & $9(52.9)$ & $32(43.8)$ & & 0.416 \\
\hline & Yes & 33 (58.9) & 8 (47.1) & $41(56.2)$ & & \\
\hline
\end{tabular}


Table II. Comparison of the surviving and deceased groups for continuous (quantitative) variables

\begin{tabular}{|c|c|c|c|c|}
\hline Outcome & Surviving & Deceased & Total & $P$-value \\
\hline Age & $58.57 \pm 14.33$ & $70.96 \pm 11.39$ & $61.63 \pm 14.63$ & 0.001 \\
\hline $\mathrm{Hb}$ & $12.38 \pm 2.23$ & $10.59 \pm 1.73$ & $11.97 \pm 2.25$ & 0.001 \\
\hline Neutrophils (\%) & $68.22 \pm 10.43$ & $71.77 \pm 12.39$ & $69.03 \pm 10.95$ & 0.201 \\
\hline Lymphocytes/neutrophils & $0.36 \pm 0.20$ & $0.29 \pm 0.22$ & $0.35 \pm 0.20$ & 0.166 \\
\hline Lymphocytes (\%) & $23(82-5)$ & $17(42-4)$ & $22(82-4)$ & 0.086 \\
\hline Hospital stay [days] & $8(29-3)$ & $7(29-3)$ & $8(29-3)$ & 0.862 \\
\hline Tumor size [mm] & $40(190-4)$ & $55(110-25)$ & $45(190-4)$ & 0.203 \\
\hline T stage & $3(4-0)$ & $3(4-0)$ & $3(4-0)$ & 0.058 \\
\hline N (total) & $12(72-1)$ & $18(45-4)$ & $14.5(72-1)$ & 0.159 \\
\hline$N(+)$ & $0(13-0)$ & $1(44-0)$ & $0(44-0)$ & 0.009 \\
\hline $\mathrm{N}(+) /$ total $\mathrm{N}$ & $0(0.75-0)$ & $0.08(0.98-0)$ & $0(0.98-0)$ & 0.012 \\
\hline Thrombocytes $\left(\times 10^{3}\right)$ & $290(968-144.7)$ & 345.85 (607-71) & $298.8(968-71)$ & 0.047 \\
\hline WBC & 8305 (18670-3480) & $9570(16760-4520)$ & 8330 (18670-3480) & 0.299 \\
\hline RDW\% & $16(33-4)$ & $17(23-13)$ & $16(33-4)$ & 0.073 \\
\hline PDW & $43.45(71.7-16.05)$ & $44.4(56.8-15.82)$ & $43.9(71.7-15.82)$ & 0.988 \\
\hline
\end{tabular}

Table III. Calculation of the cut-off levels of the statistically significant continuous parameters in Table II using the ROC curve analysis

\begin{tabular}{|c|c|c|c|c|c|c|}
\hline \multirow[t]{2}{*}{ Parameter } & & \multicolumn{2}{|c|}{ Outcome } & \multirow[t]{2}{*}{$\mathrm{AUC} \pm \mathrm{SE}$} & \multirow[t]{2}{*}{ Odds ratio $(95 \% \mathrm{Cl})$} & \multirow[t]{2}{*}{$P$-value } \\
\hline & & Surviving & Deceased & & & \\
\hline \multirow[t]{2}{*}{ Age } & $\leq 63$ & $44(57.9)^{\star *}$ & $4(16)$ & $0.759 \pm 0.055$ & $7.7(2.1-28.8)$ & $<0.001$ \\
\hline & $>63$ & $32(42.1)$ & $21(84)^{*}$ & & & \\
\hline \multirow[t]{2}{*}{$\mathrm{Hb}$} & $>12.8$ & $30(40.5)^{\star \star}$ & $1(4.5)$ & $0.721 \pm 0.057$ & $13.9(1.7-109.6)$ & $<0.001$ \\
\hline & $\leq 12.8$ & $44(59.5)$ & $21(95.5)^{\star}$ & & & \\
\hline \multirow[t]{2}{*}{$N(+)$} & $\leq 3$ & $68(93.2)^{\star \star}$ & $15(65.2)$ & $0.656 \pm 0.069$ & $7.1(1.9-25.8)$ & 0.025 \\
\hline & $>3$ & $5(6.8)$ & $8(34.8)^{*}$ & & & \\
\hline \multirow[t]{2}{*}{$\mathrm{N}(+) /$ total $\mathrm{N}$} & $\leq 0.0435$ & $53(72.6)^{\star \star}$ & $9(39.1)$ & $0.655 \pm 0.069$ & $3.8(1.4-10.7)$ & 0.024 \\
\hline & $>0.0435$ & $20(27.4)$ & $14(60.9)^{*}$ & & & \\
\hline \multirow[t]{2}{*}{ Thrombocytes $\left(\times 10^{3}\right)$} & $\leq 308$ & $44(59.5)^{\star \star}$ & $7(31.8)$ & $0.637 \pm 0.072$ & $3.1(1.1-8.6)$ & 0.059 \\
\hline & $>308$ & $30(40.5)$ & $15(68.2)^{\star}$ & & & \\
\hline
\end{tabular}

ROC (receiver operating curve) analysis (Youden index J), AUC - area under the ROC curve, SE-standard error, Cl-confidence interval.

${ }^{*}$ Sensitivity, ${ }^{* *}$ specificity, ${ }^{a} p$-value for cut off value.

increased mortality by 3.55 (95\% Cl: $1.01-12.68)$ times, hemoglobin $\leq 12.8$ by 7.99 times $(95 \% \mathrm{Cl}: 1.05-61.01)$, and $\mathrm{N}(+)$ /total $\mathrm{N}$ ratio $>0.0435$ by $3.24(95 \% \mathrm{Cl}: 1.16-$ 9.03) times.

\section{Discussion}

Although colorectal cancers affect every age group, their incidence increases in the fifth decade and rises further thereafter. Several studies have indicated that the current prevalence of colorectal cancers under the age of 50 has increased by at least $10 \%$ compared to the past [3]. This is partly a result of improved access to information technologies and advances in diagnostic medical tools. The youngest patient in our study group was 29 years old and the oldest was 87 years old. Although the disease prevalence is 1.3-2 times greater in men than in women, there exist some variations in gender-based prevalence of the disease in the literature 
Table IV. Comparison of the surviving and deceased groups for preoperative and postoperative CEA/CA 19-9 levels

\begin{tabular}{lcccc}
\hline Outcome & $\begin{array}{c}\text { Surviving } \\
\text { Median (max.-min.) }\end{array}$ & $\begin{array}{c}\text { Deceased } \\
\text { Median (max.-min.) }\end{array}$ & $\begin{array}{c}\text { Total } \\
\text { Median (max.-min.) }\end{array}$ & P-value \\
\hline CEA: & & & & \\
\hline Preop = I & $2.31(152-0)$ & $4.37(100-1.0)$ & $2.52(152-0)$ & 0.167 \\
\hline Postop = II & $1.34(67.9-0)$ & $6.16(63.5-0.4)$ & $1.60(67.9-0)$ & 0.002 \\
\hline Difference (I-II) & $0.46(151.7-9.9)$ & $1.33(7.7-5.1)$ & $0.5(151.7-9.9)$ & 0.637 \\
\hline P-value & 0.022 & 0.576 & & 0.977 \\
\hline CA 19-9: & & & & 0.131 \\
\hline Preop $=$ I & $8.46(161.5-0)$ & $10.415(700-0)$ & $9.84(700-0)$ & 0.667 \\
\hline Postop = II & $9.26(44.5-0)$ & $12.08(363-1.0)$ & $0.24(137.3-21.5)$ & \\
\hline Difference (I-II) & $0.43(137.3-21.5)$ & $-0.88(7.2--4.6)$ & 0.829 & \\
\hline P-value & 0.720 & 0.805 & & \\
\end{tabular}

Table V. Survival analysis of the statistically significant parameters in the univariate analysis

\begin{tabular}{|c|c|c|c|c|c|}
\hline Variable & $\begin{array}{c}\text { Deceased } \\
n(\%)\end{array}$ & $\begin{array}{l}\text { Surviving } \\
n(\%)\end{array}$ & $\begin{array}{l}\text { Estimate survival } \\
\qquad \text { Mean } \pm \mathrm{SE}\end{array}$ & $\begin{array}{c}\text { Estimated } \\
\text { proportion surviving } \\
\text { at } 5 \text { years }\end{array}$ & $P$-value \\
\hline \multicolumn{5}{|c|}{ Initial presentation: } & 0.028 \\
\hline Elective & $12(16.7)$ & $60(83.3)$ & $2.277 .0 \pm 152.64$ & 72.3 & \\
\hline Emergency & $9(36.0)$ & $16(64.0)$ & $1.496 .0 \pm 236.61$ & 43.2 & \\
\hline \multicolumn{5}{|c|}{ Lymphovascular invasion: } & 0.005 \\
\hline No & $9(15.8)$ & $48(84.2)$ & $2.052 .9 \pm 128.83$ & 73.1 & \\
\hline Yes & $12(37.5)$ & $20(62.5)$ & $1.366 .0 \pm 228.93$ & 39.6 & \\
\hline \multicolumn{5}{|l|}{ Age: } & 0.001 \\
\hline$\leq 63$ & $4(8.3)$ & $44(91.7)$ & $2.577 .7 \pm 142.46$ & 86 & \\
\hline$>63$ & $17(34.7)$ & $32(65.3)$ & $1.496 .6 \pm 171.34$ & 43.1 & \\
\hline \multicolumn{5}{|l|}{$\mathrm{Hb}:$} & 0.005 \\
\hline$>12.8$ & $1(3.2)$ & $30(96.8)$ & $2.756 .0 \pm 119.80$ & 93.3 & \\
\hline$\leq 12.8$ & $17(27.9)$ & $44(72.1)$ & $1.666 .4 \pm 156.03$ & 58.2 & \\
\hline \multicolumn{5}{|l|}{$N(+):$} & 0.001 \\
\hline$\leq 3$ & $12(15.0)$ & $68(85.0)$ & $2.342 .5 \pm 139.83$ & 74.6 & \\
\hline$>3$ & $7(58.3)$ & $5(41.7)$ & $1.049 .7 \pm 276.31$ & 19.3 & \\
\hline \multicolumn{5}{|l|}{$N(+) /$ total N: } & 0.001 \\
\hline$\leq 0.0435$ & $7(11.7)$ & $53(88.3)$ & $2.159 .4 \pm 114.74$ & 79 & \\
\hline$>0.0435$ & $12(37.5)$ & $20(62.5)$ & $1.544 .9 \pm 265.02$ & 40.1 & \\
\hline \multicolumn{5}{|l|}{ Thrombocytes: } & 0.010 \\
\hline$\leq 308$ & $5(10.2)$ & $44(89.8)$ & $2.185 .9 \pm 126.07$ & 82.6 & \\
\hline$>308$ & $13(30.2)$ & $30(69.8)$ & $1.856 .0 \pm 225.20$ & 57 & \\
\hline Total & $21(21.6)$ & $76(78.4)$ & $2.120 .9 \pm 140.08$ & 64.6 & \\
\hline
\end{tabular}

Kaplan-Meier test log rank (Mantel-Cox). SE - standard error. 


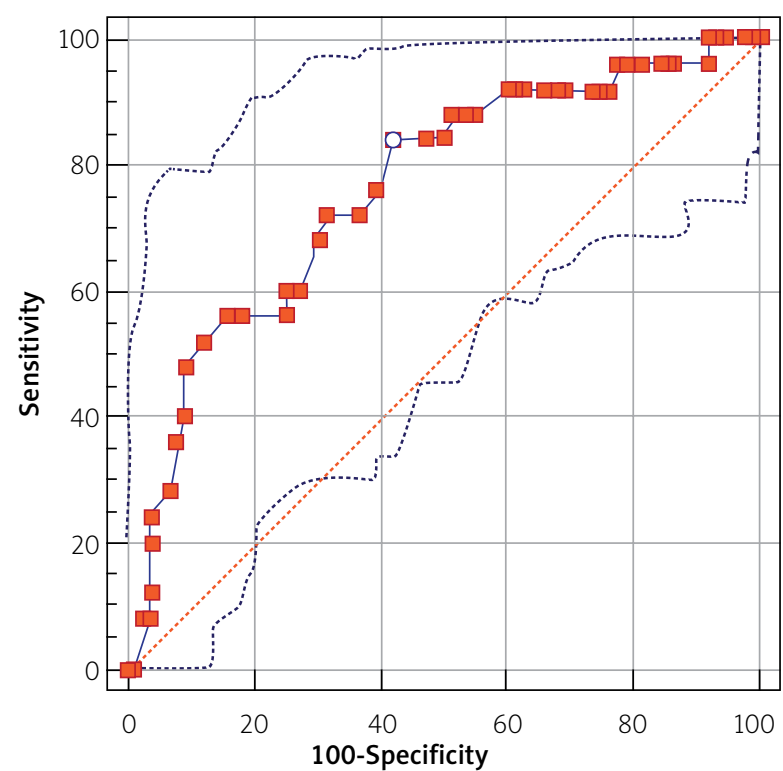

Figure 1. Area under the ROC curve for age (sensitivity $84 \%$, specificity $57.9 \%$ )

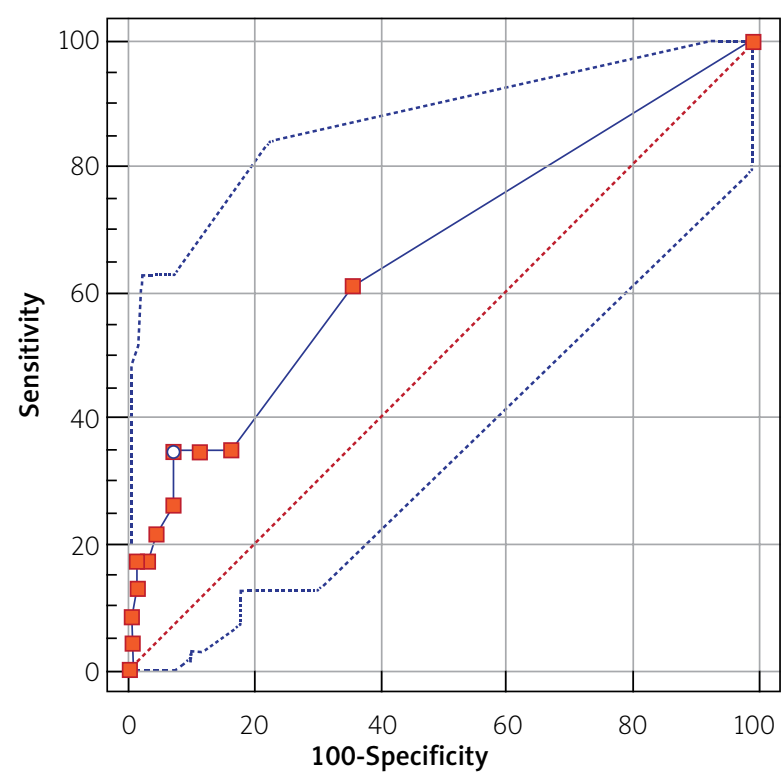

Figure 3. Area under the ROC curve for $\mathrm{N}(+)$ (sensitivity $34.8 \%$, specificity $93.2 \%$ )

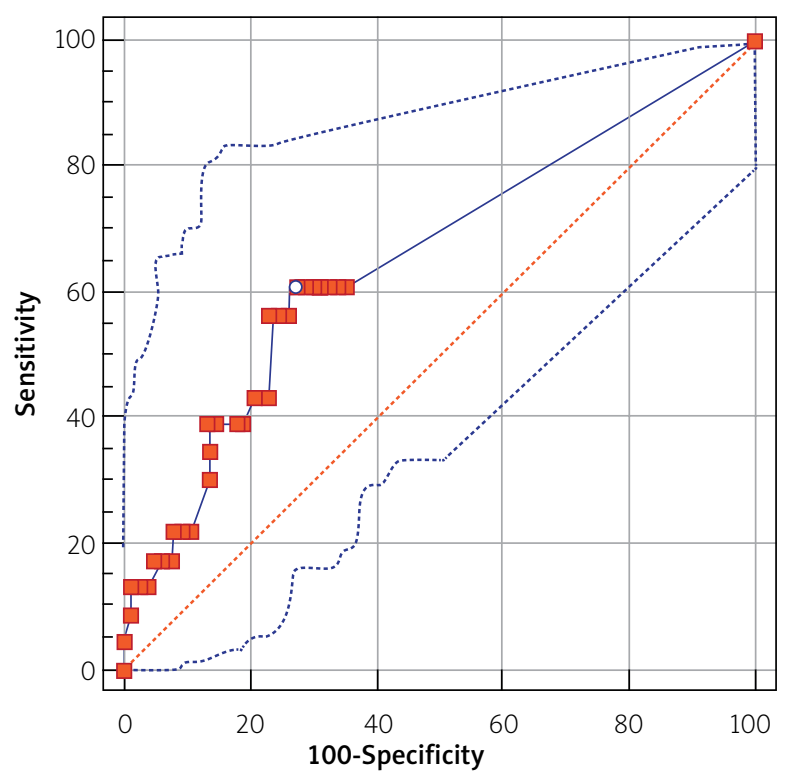

Figure 2. Area under the ROC curve for $\mathrm{N}(+)$ /total N (sensitivity $60.9 \%$, specificity $72.6 \%$ )

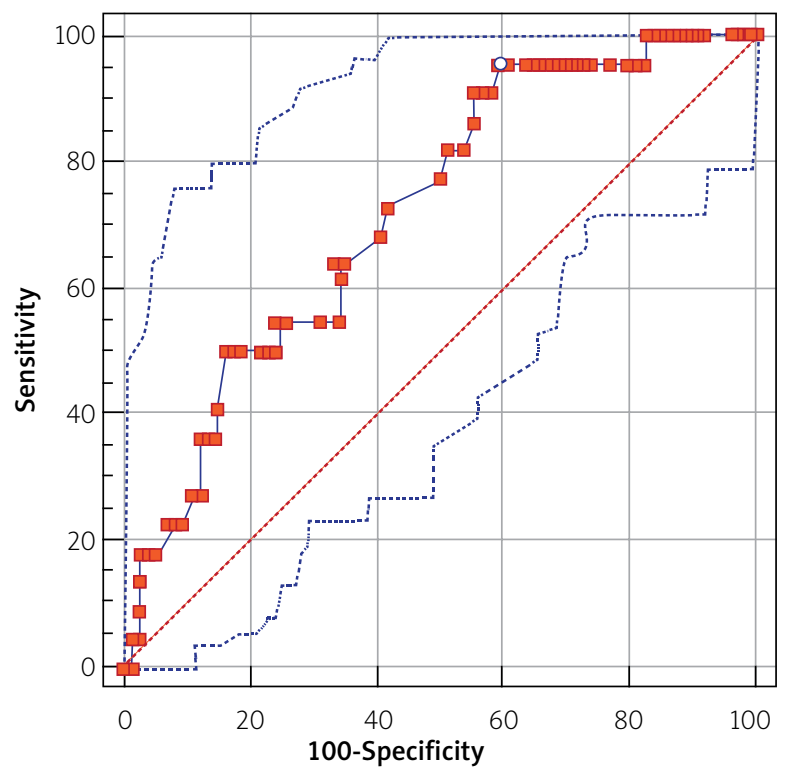

Figure 4. Area under the ROC curve for $\mathrm{Hb}$ (sensitivity $95.5 \%$, specificity $40.5 \%$ )

Table VI. Analysis of the statistically significant parameters for survival using the Cox regression model

\begin{tabular}{lccc} 
Parameter & B \pm SE & $P$-value & Odds ratio $(95 \%$ Cl) \\
\hline Age $(>63)$ & $1.27 \pm 0.65$ & 0.049 & $3.55(1.01-12.68)$ \\
\hline $\mathrm{Hb}(\leq 12.8)$ & $2.08 \pm 1.04$ & 0.045 & $7.99(1.05-61.01)$ \\
\hline $\mathrm{N}(+) /$ total $\mathrm{N}(>0.0435)$ & $1.18 \pm 0.52$ & 0.025 & $3.24(1.16-9.03)$
\end{tabular}

Cox regression - backward stepwise (Wald) method. B - regression coefficients, SE-standard error, CI-confidence interval. 
$[4,5]$. Our study population similarly had a male/female ratio of $1.4 / 1$, and the gender difference between the alive and dead groups was non-significant. Several studies have identified age at diagnosis as an important prognostic factor whereas some others have reported the opposite [6-8]. Although some debate still exists, previous studies predominantly identified age $(\geq 90$ years), ASA score $\geq 3$, undergoing combined surgery, low hemoglobin level $(<10 \mathrm{~g} / \mathrm{dl})$ and low albumin level $(<3.4 \mathrm{~g} / \mathrm{dl})$ as independent risk factors for postoperative 30-day mortality. The major prognostic factors for postoperative 1-year mortality include an ASA score $\geq 3$, a TNM stage of IV, and the development of postoperative complications [6-8]. Our study identified age at diagnosis as an important prognostic factor. We found a significant 7.7-fold (95\% Cl: 2.1-28.8) increase in mortality risk among patients older than 63 years compared to those aged equal to or less than 63 years. This difference may have resulted from the challenges of cancer treatment and the poor general health status of colorectal cancer patients.

Patients with colorectal cancer usually initially present with rectal bleeding, constipation, obstructive complaints, abdominal pain, weight loss, loss of appetite, anemia, abdominal mass, metastasis-related complaints, and rarely atypical complaints. Our patients also had predominantly $(88 \%)$ rectal bleeding, altered bowel habits (constipation, obstructive complaints of varying intensity), and abdominal pain. No significant difference existed between the alive and dead patient groups with respect to the admission complaints. However, the mortality rate of patients who presented to the emergency department and who subsequently underwent surgery was 2.9 (95\% Cl: 1.1-7.7) times greater than that of those who were operated on on an elective basis.

Several studies in the literature have shown that quantitative real-time reverse transcription-PCR (qRT$P(R)$ is an independent predictor for the detection of nodal micrometastases and circulating tumor cells in patients with colorectal cancer $[9,10]$. It has also been shown that a high preoperative D-dimer level was associated with a worse prognosis than a low D-dimer level $[11,12]$. We did not routinely study the preoperative D-dimer level or postoperative qRT-PCR. It was previously reported that a high preoperative neutrophil/lymphocyte ratio prior to chemoradiotherapy was an adverse prognostic sign (10). It was also found that a high preoperative platelet level was an independent risk factor for colorectal cancer mortality and metastasis [13]. Our study identified significant differences between hemoglobin level $(p=0.001)$ and thrombocyte count ( $p=0.047$ ) of the two groups but it failed to detect any significant difference for other continuous variables.
That is, neutrophil/lymphocyte ratio had no prognostic significance but a high platelet count was associated with worse prognosis and more frequent recurrence. In contrast, a high hemoglobin level was a predictor of a significantly better prognosis ( $p=0.045$ ) (a hemoglobin level of $\leq 12.8$ was associated with a 7.99 times higher mortality risk). Lymphovascular and perineural invasion is associated with mortality from colorectal cancers [14]. Similarly, lymphovascular invasion ( $p=$ $0.005)$ and a $\mathrm{N}(+)$ /total $\mathrm{N}$ ratio of greater than 0.0435 $(p=0.001)$ were significant predictors of mortality, as was indicated previously in the literature.

Regional lymph node metastasis is the most important prognostic factor in patients with colorectal cancer $[10,15]$. While there is a theoretical risk for recurrence of $25 \%$ in patients who are cancer free (pNo) after surgery, this risk exceeds $50 \%$ in patients with metastases to 4 or more lymph nodes (pN2,3,4) $[16,17]$. It has been reported that guanylyl cyclase C (GUCY2C) and qRT-PCR effectively showed occult metastases in patients with stage cancer pNO $[9,10,18]$. The histopathological evaluation of patients receiving neoadjuvant radiotherapy showed that recurrences are more frequent in patients with a high tumor regression grade (TRG) [19]. Many randomized clinical studies have so far reported that adjuvant chemotherapy and close follow-up are useful to improve postoperative patient surveillance. The postoperative surveillance of patients undergoing colorectal surgery can be performed using abdomen/pelvis CT (CT $A / P$ ) or abdominal ultrasonography (AUS) to visualize the abdominopelvic region; X-ray (CXR) or CT of the chest to visualize the thoracic region; endoscopy in the form of flexible sigmoidoscopy or colonoscopy; or tumor markers such as CEA [20-22]. Although CEA is not specific for colorectal cancer, it is an important tumor marker with a sensitivity of 34-64\% which is used for follow-up [22, 23]. However, it has been reported that colonoscopic surveillance and especially the CEA test are not routinely performed for follow-up in a majority of patients. Although our study also revealed a significant difference between the postoperative CEA values of the alive and dead groups $(p=0.002)$, CEA level was determined in only $60 \%(n=60)$ of the patients.

One of the major findings of our study is that patients who presented to the emergency department and who were subsequently operated on for colorectal cancer have an increased risk of death, necessitating a more aggressive and careful treatment approach. Despite this, excess mortality resulting from independent risk factors can be reduced but not completely eliminated. Although colorectal cancers are associated with high overall mortality, higher success rates can be achieved in early stage cancer, which necessitates novel efforts 
to prevent cancer spread and to develop methods facilitating early diagnosis, which is the only way to reduce the mortality from these cancers.

\section{Conclusions}

A univariate analysis revealed significant differences between the groups with respect to type of presentation, lymphovascular invasion, age, $\mathrm{Hb}, \mathrm{N}(+), \mathrm{N}(+)$ /total $\mathrm{N}$, and thrombocyte levels. A ROC curve was used to determine the best cut-off points for the significant predictors of mortality in the univariate analysis. At the specified cut-off points, age (>63), $\mathrm{Hb}(\leq 12.8), \mathrm{N}(+)$ $(>3)$ and $\mathrm{N}(+)$ /total $\mathrm{N}(>0.435)$ levels were significantly associated with mortality. Kaplan-Meier test log rank (Mantel-Cox) analysis showed that the 5-year survival was worse in patients with emergency presentation, lymphovascular invasion, age $>63, \mathrm{Hb} \leq 12.8, \mathrm{~N}>3$, $\mathrm{N}(+)$ /total $\mathrm{N}>0.0435$, and thrombocyte count $>308$ compared to other patients. A multivariate analysis using the Cox regression backward stepwise (Wald) method demonstrated that age (> 63), $\mathrm{Hb}(\leq 12.8)$, and $\mathrm{N}(+)$ / total $\mathrm{N}(>0.0435)$ ratio were significant predictors of mortality. The retrospective design and the small sample volume prevents us from making robust suggestions for the predictors of colorectal cancer mortality. However, the robust systematics of the statistical analyses of this study and its statistically significant results make this study worth publishing.

\section{Conflict of interest}

The authors declare no conflict of interest.

\section{References}

1. Azeem K, Sevcikova J, Kysely Z, et al. Primary and secondary prevention of colorectal cancer in the Czech Republic. Prz Gastroenterol 2016; 11: 1-5.

2. Stańko G, Kamiński M, Bogacz A, et al The importance of G2677T/A and C3435T polymorphisms of the MDR1 gene in the aetiology of colorectal cancer. Prz Gastroenterol 2016; 11: 35-40.

3. Myers EA, Feingold DL, Forde KA, et al. Colorectal cancer in patients under 50 years of age: a retrospective analysis of two institutions' experience. World J Gastroenterol 2013; 19: 5651-7.

4. Howlader N, Noone AM, Krapcho M, et al. SEER Cancer Statistics Review, 1975-2009, National Cancer Institute. Bethesda, MD, 2012. Available from: URL: http:// seer.cancer.gov/ csr/1975_2010/

5. Abdulkareem FB, Abudu EK, Awolola NA, et al. Colorectal carcinoma in Lagos and Sagamu, Southwest Nigeria: a histopathological review. World J Gastroenterol 2008; 14: 6531-5.

6. Kim YW, Kim IY. Factors associated with postoperative complications and 1-year mortality after surgery for colorectal cancer in octogenarians and nonagenarians. Clin Interv Aging 2016; 11: 689-97.
7. Park YJ, Park KJ, Park JG, et al. Prognostic factors in 2230 Korean colorectal cancer patients: analysis of consecutively operated cases. World J Surg 1999; 23: 721-6.

8. Widdison AL, Barnett SW, Betambeau N. The impact of age on outcome after surgery for colorectal adenocarcinoma. Ann R Coll Surg Engl 2011; 93: 445-50.

9. Koyanagi K, Bilchik AJ, Saha S, et al. Prognostic relevance of occult nodal micrometastases and circulating tumor cells in colorectal cancer in a prospective multicenter trial. Clin Cancer Res 2008; 14: 7391-6.

10. Hyslop T, Weinberg DS, Schulz S, et al. Occult tumor burden predicts disease recurrence in lymph node-negative colorectal cancer. Clin Cancer Res 2011; 17: 3293-303.

11. Stender MT, Larsen TB, Sorensen HT, et al. Preoperative plasma D-dimer predicts 1-year survival in colorectal cancer patients with absence of venous thromboembolism (VTE): a prospective clinical cohort study. J Thromb Haemost 2012; 10: 2027-31.

12. Kim IY, You SH, Kim YW. Neutrophil-lymphocyte ratio predicts pathologic tumor response and survival after preoperative chemoradiation for rectal cancer. BMC Surg 2014; 14: 94.

13. Wan S, Lai Y, Myers RE, et al. Preoperative platelet count associates with survival and distant metastasis in surgically resected colorectal cancer patients. J Gastrointest Cancer 2013; 44: 293-304.

14. Knijn N, Mogk SC, Teerenstra S, et al. Perineural invasion is a strong prognostic factor in colorectal cancer: a systematic review. Am J Surg Pathol 2016; 40: 103-12.

15. Wu ZY, Wan J, Li JH, et al. Prognostic value of lateral lymph node metastasis for advanced low rectal cancer. World J Gastroenterol 2007; 13: 6048-52.

16. Compton CC, Greene FL. The staging of colorectal cancer: 2004 and beyond. CA Cancer J Clin 2004; 54: 295-308.

17. Jemal A, Siegel R, Ward E, et al. Cancer statistics, 2007. CA Cancer J Clin 2007; 57: 43-66.

18. Nicastri DG, Doucette JT, Godfrey TE, Hughes SJ. Is occult lymph node disease in colorectal cancer patients clinically significant? A review of the relevant literature. J Mol Diagn 2007; 9: 563-71.

19. Peng YF, Yu WD, Pan HD, et al. Tumor regression grades: potential outcome predictor of locally advanced rectal adenocarcinoma after preoperative radiotherapy. World I Gastroenterol 2015; 21: 1851-6.

20. Wang L, Gu GL, Li ZW, et al. Abdominoperineal excision following preoperative radiotherapy for rectal cancer: unfavorable prognosis even with negative circumferential resection margin. World J Gastroenterol 2014; 20: 9138-45.

21. Tan J, Muir J, Coburn N, et al. Surveillance patterns after curative-intent colorectal cancer surgery in Ontario. Can J Gastroenterol Hepatol 2014; 28: 427-33.

22. Hu CY, Delclos GL, Chan W, et al. Post-treatment surveillance in a large cohort of patients with colon cancer. Am J Manag Care 2011; 17: 329-36.

23. Tan E, Gouvas N, Nicholls RJ, et al. Diagnostic precision of carcinoembryonic antigen in the detection of recurrence of colorectal cancer. Surg Oncol 2009; 18: 15-2.

Received: 29.08.2017

Accepted: 7.11.2017 